\title{
Factors affecting functional outcomes of traumatic brain injury rehabilitation at a rehabilitation facility in Saudi Arabia
}

Sami Ullah, MBBS, FCPS (PMR), Saeed BinAyaz, MBBS, FCPS (PMR), ImadS. Moukais, MBBS, JBPMR, AhmadZ. Qureshi, MBBS, FCPS (PMR), Talal Alumri, MBBS, Tariq A. Wani, MSc, Adel A. Aldajani, MBChB, FAFRM (RACP).

\begin{abstract}
الأهداف : وصف أنماط مدة التنويم في المستشفيات والوقت اللازم لبرامج الماتج

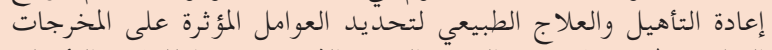

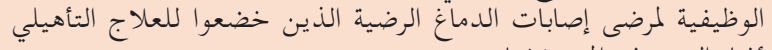
أثناء التنويم في المستشفيات.

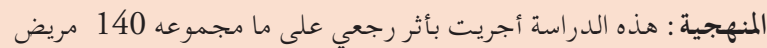

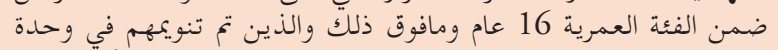

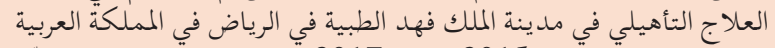

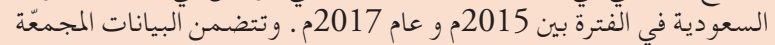

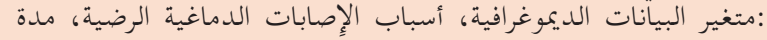

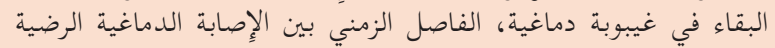

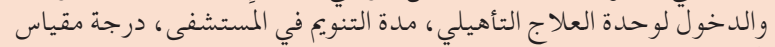

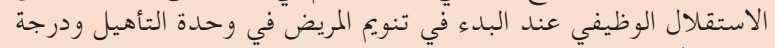
مقياس الاستقلال آلوظيفي عن انتهاء تنويم المريض "وخروجي لونه من الوححدة. النتائج : أظهرت الدراسة أن الحوادث المرورية تشكل ب5 95 من الإصابات

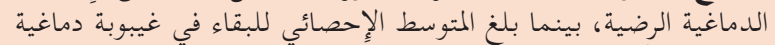

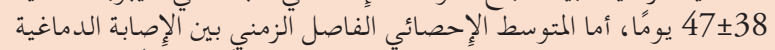

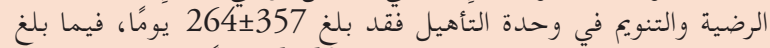
المتوسط الإحصائي للتنويم في المستشفى

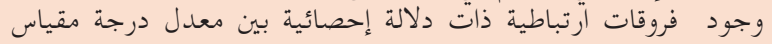

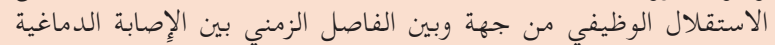

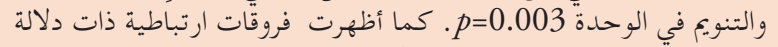

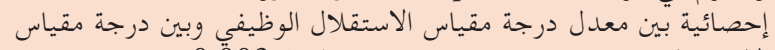

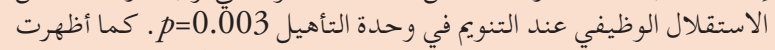

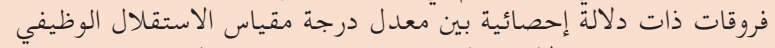

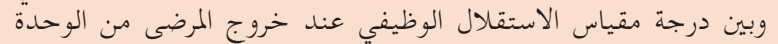

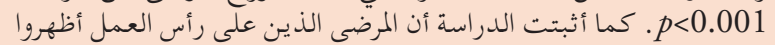

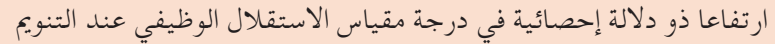
.p=0.029

الحلاصة : يجب النظر في التدابير المناسبة لمنع الحوادث المرورية في المملكة

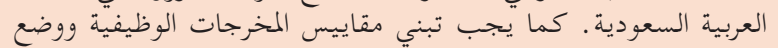

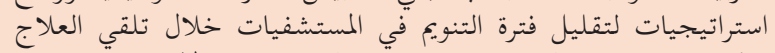

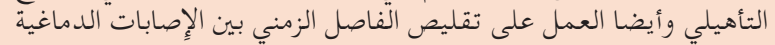
الرضية والتنويم في وحدة العلاج التأهيلي.
\end{abstract}

Objectives: To identify the factors that affect disability after inpatient rehabilitation (IPR) in persons with traumatic brain injury (TBI).
Methods: This retrospective study identified 140 patients aged $\geq 16$ years who were admitted to the TBI rehabilitation unit at King Fahad Medical City, Riyadh, Kingdom of Saudi Arabia between 2015 and 2017. The collected data included demographic variables, TBI cause, coma duration, time from injury to IPR, LOS, and Functional Independence Measure (FIM) scores at IPR admission and discharge.

Results: Majority of the patients were young males. The TBI was caused by motor vehicle accidents (MVA) in $95 \%$ of patients. The mean coma duration, time from injury to IPR admission, and LOS were $47 \pm 38$, $264 \pm 357$, and $75 \pm 52$ days, respectively. The factors that were found to have an association with FIM change were time from injury to IPR admission $(p=0.003$, $\mathrm{r}=-0.250)$, admission FIM score $(p=0.003, \mathrm{r}=-0.253)$, and discharge FIM score $(p<0.001, \quad \mathrm{r}=0.390)$. Employed patients had high FIM scores at admission $(p=0.029, \mathrm{r}=0.184)$ and discharge $(p=0.003, \mathrm{r}=0.252)$.

Conclusion: Reduction in disability at discharge was positively associated with the severity of disability at admission and negatively with the time duration from injury to IPR admission, indicating a need to reduce time before admittance to an IPR setup. The high incidence of MVA causing TBI in a young male population strongly points to a need for appropriate measures of prevention.

Neurosciences 2020; Vol. 25 (3): 169-175 doi: 10.17712/nsj.2020.3.20190097

From the Department of Physical Medicine and Rehabilitation (Ullah, Moukais, Oureshi, Aldajani), and Department of Biostatistics (Wani), Research Services Administration, Research Center, King Fahad Medical City, from National Guard Hospital (Alumri), Riyadh, Kingdom of Saudi Arabia, and from the Department of Physical Medicine and Rehabilitation (Bin Ayaz), Combined Military Hospital Jhelum, Punjab, Pakistan.

Received 23rd October 2019. Accepted 14th April 2020.

Address correspondence and reprint request to: Dr. Sami Ullah, Department of Physical Medicine and Rehabilitation, Rehabilitation Hospital, King Fahad Medical City, Riyadh, Kingdom of Saudi Arabia.E-mail:drsamipmr@gmail.com

ORCID ID https://orcid.org/0000-0002-1329-7347 
T raumatic brain injury (TBI) is a major public health problem worldwide and is associated with high rates of mortality and disability. Recent data have revealed that TBI is responsible for more than 4.5 million deaths a year. ${ }^{1}$ In the near future, this value is expected to rise owing to increasing population density, aging, and increasing numbers of motor vehicles and motor vehicle accidents (MVA) worldwide, particularly in Arab countries. ${ }^{2}$ The TBI survivors might have permanent disabilities, leaving them with long-standing cognitive, physical, and psychosocial difficulties. This may in turn exert considerable financial burden on the healthcare system. ${ }^{3}$ The clinical outcome after TBI depends on the clinical presentation of the affected individual as well as on timely management by the treatment team.

The acute medical management following TBI is focused on saving life, maintaining cerebral perfusion, management of sympathetic hyperactivity, and prophylaxis and prompt treatment of intracranial hypertension and secondary brain injury. ${ }^{4}$ During the acute phase, after initial stabilization, a team of health professionals focus to optimize physical and cognitive function through intensive therapy targeted on cognition, communication, self-care, mobility, and behavior. ${ }^{5}$ This initial therapy is termed acute rehabilitation while the patient is still admitted for acute management of TBI. After acute care, the patients may be transferred to a sub-acute or inpatient rehabilitation (IPR) facility if they are medically appropriate to participate in more intensive therapies. IPR or subacute rehabilitation is followed by daycare rehabilitation, home care, long-term facility or outpatient therapies. In post-trauma care, IPR is important for returning to functional independence. Several factors influence outcomes despite a similar treatment approach in different IPR facilities. The factors predictive of improved functional outcomes after IPR include the functional status at admission, injury severity, age, gender, race, associated comorbidities, time from injury to IPR admission, and IPR length of stay (LOS). ${ }^{6}$ The incidence of TBI in Saudi Arabia has been inferred to be 116 per 100,000 population. ${ }^{7}$ In spite of this, there is a deficiency of data regarding epidemiology, social attributes, and factors affecting outcomes in TBI rehabilitation. Therefore, the present study aimed to

Disclosure. Authors have no conflict of interests, and the work was not supported or funded by any drug company. describe the trends in LOS and time to rehabilitation and to identify the factors that affect disability after IPR among patients with TBI in Saudi Arabia.

Methods. Design. This retrospective cohort study was conducted in a tertiary healthcare hospital and approved by the Research Ethics Committee. Considering the nature of this study, informed consent was not required.

Subjects. The data were collected from the medical records of patients with TBI who underwent an IPR program at King Fahad Medical City, Riyadh, Kingdom of Saudi Arabia between 2015 and 2017. Data were initially screened to identify individuals documented to have TBI based upon International Statistical Classification of Diseases and Related Health Problems diagnostic coding (ICD-Code-10). ${ }^{8}$ All patients aged $\geq 16$ years were included in this study. Patients who died and those who transferred to acute care were excluded. Majority of the patients were admitted directly into the IPR setup without being managed at the acute medical care setup of our hospital.

Procedure. The information collected from the chart review included demographic information, causes of injury, comorbidities, complications of TBI, initial Glasgow Coma Scale (GCS) score in the emergency department, time from injury to IPR admission, LOS, and Functional Independence Measure (FIM) scores at IPR admission and discharge. As majority of patients were enrolled without receiving initial medical care at our hospital, the documentation was deficient with regard to post-traumatic amnesia (PTA); thus, PTA was not included in documentation.

Outcome measures. The FIM is a tool to evaluate functional independence in terms of cognition, mobility, and self-care. It is a validated tool and measures disability with 18 items rated on a scale from 1 (complete dependence) to 7 (complete independence). ${ }^{9}$ The total score range is $18-126$, and a higher score indicates a higher level of independence. It has 2 sub-domains i.e. motor function and cognitive function. The score range for motor function is 13-91 while for cognitive function the range is 5-35. Furthermore, the difference between the FIM score at admission and at discharge was calculated and termed as FIM change.

Analysis. Correlation of these factors with functional outcomes and LOS during IPR were the primary end-points of the study. Statistical Package for the Social Sciences v 20.0 (SPSS Inc., Chicago, IL, USA) was used for the data analysis. Data are presented as averages (means \pm standard deviations) and percentages (frequencies and \%). Bivariate correlation analysis 
by the Karl-Pearson method was performed for data evaluated during the study. All inferences were made at $95 \%$ confidence interval, and a $p$-value $<0.05$ was considered significant. The effect size was measured through correlation coefficient " $r$ " while following the Cohen's recommendations, which states that the effect size is small if the value of " $r$ " varies between 0.1 to 0.3 , medium if " $r$ " values from 0.3 to 0.5 , and large if " $r$ " values from 0 . to 1.0 .

Ethics. The study was conducted after obtaining approval from the institutional review board (IRB) of King Fahad Medical City, Riyadh, Kingdom of Saudi Arabia with IRB approval number 17-480.

Results. This retrospective investigation identified 140 patients after excluding three patients who were transferred to acute care. The mean patient age was $27 \pm 11$ years (range: $16-80$ years), and the patients were predominantly male (92\%) and single (72.1\%) (Table 1$)$. The TBI was caused by MVAs in $95 \%$ of patients. The mean initial GCS score after trauma in the ED was $6 \pm 2$

Table 1 - Descriptive statistics for categorical variables $(\mathrm{N}=140)$

\begin{tabular}{ll}
\hline Categorical variables & $\mathbf{n}(\%)$ \\
\hline Gender: Male/Female & $11 / 129(8: 92)$ \\
Marital status & \\
Single & $101(72.1)$ \\
Married & $33(23.6)$ \\
Widowed & $6(4.3)$ \\
Educational level & \\
Illiterate & $3(2.1)$ \\
Primary school & $8(5.7)$ \\
Secondary school & $63(45.0)$ \\
Intermediate school & $12(8.6)$ \\
High school & $4(2.9)$ \\
College & $47(33.6)$ \\
Postgraduate degree & $3(2.1)$ \\
Occupation & \\
Student & $61(43.6)$ \\
Unemployed & $23(16.4)$ \\
Self employed & $19(13.5)$ \\
Security forces & $23(16.4)$ \\
Driver & $3(2.1)$ \\
Farmer & $1(0.7)$ \\
Teacher & $5(3.6)$ \\
House Wife & $5(3.6)$ \\
Cause of injury & \\
Assault & $1(0.7)$ \\
Fall & $2(1.4)$ \\
MVA & $133(95.0)$ \\
Other & $4(2.9)$ \\
Body site affected & \\
Tetraplegia & \\
Left Hemiplegia & $100(71.4)$ \\
Right Hemiplegia & $26(18.6)$ \\
Paraplegia & $11(7.9)$ \\
& $3(2.1)$ \\
\hline & \\
& MVA - Motor vehicle accident \\
& \\
\hline & \\
&
\end{tabular}

(range: $0-15$ ), and the mean coma duration was $47 \pm 38$ days (range: 3-180 days). The mean time from injury to IPR admission was $264 \pm 357$ days (range: $32-2220$ days), and the mean IPR LOS was $75 \pm 52$ days (range: 10-373 days). The mean FIM scores at admission and discharge were $54 \pm 31$ (range: $18-126$ ) and $87 \pm 33$ (range: 18-126) respectively, with a mean FIM change of $33 \pm 21$ (range: $0-86$ ). Most $(43.6 \%)$ of the patients were students, and nearly two-third of the patients were admitted with tetraplegia (71.4\%). Additionally, nearly two-third $(72.1 \%)$ of the patients had fractures other than skull fractures, and one-third $(28.5 \%)$ were diagnosed with seizure disorder after TBI (Table 2).

The factors significantly correlated with FIM change were FIM at admission $(p=0.003, r=-0.253)$, FIM at discharge $(p<0.001, \mathrm{r}=0.390)$, and time from injury to IPR admission ( $p=0.003, \mathrm{r}=-0.250)$ (Table 3). Patients who were employed before the injury had high FIM scores upon admission $(p=0.029, \mathrm{r}=0.184)$ and discharge $(p=0.003, r=0.252)$. Older patients had low FIM scores at admission $(p=0.004, r=-0.244)$ and discharge $(p<0.001, \mathrm{r}=-0.330)$. Additionally, patients with a long coma duration after TBI and those with a long IPR LOS had lower FIM scores at admission $(p<0.001)$ and discharge $(p<0.001)$. Thus, coma duration and IPR LOS had moderate to large negative associations with FIM indicating worse outcomes and more disability with extension in time of coma duration and IPR LOS. Moreover, patients with a longer time from injury to IPR admission had a lower FIM score at discharge $(p<0.003, \mathrm{r}=-0.253)$.

Table 2 - Comorbidities and complications associated with traumatic brain injury in 140 patients

\begin{tabular}{lc}
\hline Comorbidities and complications & $\mathbf{n}(\%)$ \\
\hline Comorbidities & \\
Diabetes mellitus & $3(2.1)$ \\
Respiratory disease & $10(7.1)$ \\
Chronic Kidney Disease & $5(3.6)$ \\
Hypertension & $6(4.3)$ \\
Heart Disease & $3(2.1)$ \\
Complications & \\
Fractures other than the skull & $101(72.1)$ \\
Seizures & $40(28.5)$ \\
Dysautonomia & $3(2.1)$ \\
Heterotopic ossification & $48(34.3)$ \\
Cranial nerve involvement & $60(42.9)$ \\
Contractures & $71(50.7)$ \\
Deep vein thrombosis & $3(2.1)$ \\
Pulmonary embolism & $4(2.9)$ \\
Movement disorder & $3(2.1)$ \\
Mental disorders & $82(59.9)$ \\
Pressure ulcer & $23(16.4)$ \\
Associated spinal cord injury & $4(2.9)$ \\
\end{tabular}


Discussion. The TBI is becoming an important reason of preventable deaths in Saudi Arabia. We found MVA responsible for TBI in 95\% patients. Other Saudi studies have also found MVA responsible for TBI in $89.3 \%, 69.4 \%$, and $71.8 \%$ of patients. ${ }^{10-12}$ These findings are consistent with regional reports from Qatar, Egypt, United Arab Emirates, Kuwait, and Sudan. ${ }^{13-16}$ Over-speeding remains a major concern in the Middle East, and it is associated with high velocity accidents in which brain injury is most likely to occur. Hence, appropriate measures for the prevention of MVA need to be considered in the region. This can be achieved by establishing advanced data record system, legislation and enforcement, awareness campaigns and education programs, induction of traffic and speed reduction measures, identification of susceptible crash sites, and engagement and coordination of key stake holders including ministry of health. ${ }^{17,18}$

The majority of the sampled patients were young males (average age: 27 years), similar to findings of regional studies in which TBI was found to be more frequent in younger males., $71,13-16,19,20$ The higher percentage of males than females was probably because the bulk majority of pedestrians and drivers on roads in Saudi Arabia are mostly males and therefore they are mostly involved in MVA. ${ }^{6,12,21}$ Saudi government has extended driving privileges to females in 2018 and availability of a female driver in the family may bar the younger males from driving in case of a commute requirement. Additionally, an analysis of human psychology suggests that young people consider driving a representation of autonomy, adulthood, and an opportunity to enjoy thrill associated with risky behaviors. ${ }^{21}$ There are gender and age differences in MVAs which can be addressed by strict implementation of age-bound restriction on driving.

The most important factor to affect functional outcome in our study was time to start rehabilitation after injury. Those patients who entered a rehabilitation program earlier had a better functional outcome at discharge. Likewise, Demir et $\mathrm{a}^{22}$ compared early and late rehabilitation and found that there was a significant improvement with early rehabilitation. Andelic et $\mathrm{al}^{23}$ also noted better functional outcomes in patients who received early rehabilitation. Additionally, Tepas et $\mathrm{al}^{24}$ discovered that rehabilitation delay reduced the effectiveness of rehabilitative care. Moreover, other studies have also reported that the time to IPR admission was related to the FIM score. ${ }^{6,25,26}$ The second factor worth mentioning is the FIM at admission. The patients with lower FIM at admission or in other words more disability at admission had better functional recovery or superior reduction in disability at the end of the IPR period. Qannam et $\mathrm{al}^{6}$ also, identified the FIM score at admission as the largest contributor to FIM score at discharge, which accounted for 45-65\% of the variability in the models. Similar findings have been noted in other studies as well. ${ }^{25-27}$

There were many comorbidities and complications observed by us in our study. Around $72 \%$ of patients

Table 3 - Correlations of different factors with Functional Independence Measure (FIM) scores and change (n=140).

\begin{tabular}{lcccccc}
\hline Variables & \multicolumn{2}{c}{ FIM at admission } & \multicolumn{2}{c}{ FIM at discharge } & \multicolumn{2}{c}{ FIM Change } \\
& $\mathrm{r}^{*}$ & ${ }^{* *} \boldsymbol{P}$-value & $\mathrm{r}$ & $\boldsymbol{P}$-value & $\mathrm{r}$ & $P$-value \\
\hline Age & -0.244 & 0.004 & -0.330 & $<0.001$ & -0.140 & 0.100 \\
Gender & 0.057 & 0.507 & 0.027 & 0.757 & -0.042 & 0.628 \\
Employment status & 0.184 & 0.029 & 0.252 & 0.003 & 0.115 & 0.178 \\
Education level & -0.044 & 0.604 & -0.044 & 0.609 & 0.003 & 0.973 \\
Occupation & 0.107 & 0.206 & 0.158 & 0.063 & 0.073 & 0.393 \\
Marital status & 0.150 & 0.076 & 0.182 & 0.032 & 0.052 & 0.545 \\
Cause of injury & 0.070 & 0.412 & 0.104 & 0.221 & 0.061 & 0.478 \\
Body site affected & -0.292 & $<0.001$ & -0.318 & $<0.001$ & -0.074 & 0.384 \\
Initial GCS score in the emergency department & 0.118 & 0.166 & 0.128 & 0.130 & 0.024 & 0.780 \\
Coma duration in days & -0.340 & $<0.001$ & -0.340 & $<0.001$ & -0.028 & 0.740 \\
Time from injury to admission in days & -0.101 & 0.234 & -0.253 & 0.003 & -0.250 & 0.003 \\
Length of stay in days & -0.589 & $<0.001$ & -0.622 & $<0.001$ & -0.100 & 0.242 \\
FIM at admission & 1 & - & 0.791 & $<0.001$ & -0.253 & 0.003 \\
FIM at discharge & 0.791 & $<0.001$ & 1 & - & 0.390 & $<0.001$ \\
FIM change & -0.253 & 0.003 & 0.390 & $<0.001$ & 1 & - \\
\hline \multicolumn{1}{c}{$*$ correlation coefficient, ${ }^{* *} p$-value, FIM- FIM- Functional Independence Measure, GCS - Glasgow coma scale } \\
\hline
\end{tabular}


had fractures other than skull fractures due to trauma. The most frequent complications after TBI were mental disorders $(59.9 \%)$, contractures $(50.7 \%)$, cranial nerve injuries (42.9\%), and heterotopic ossification (HO) $(34.3 \%)$. Ahmed et $\mathrm{al}^{28}$ had summarized the complications associated with TBI in Saudi population. They identified cognitive impairment, cranial nerve injuries, seizures, hydrocephalus, cerebrospinal fluid leakage, tinnitus, organ failure, and poly-trauma (including associated fractures) as short-term complications and Parkinson's disease, Alzheimer's disease, dementia, epilepsy, and several psychiatric disorders as long-term complications. In a Turkish cohort, Demir et $\mathrm{al}^{22}$ reported spasticity, seizures, dysphagia, contractures, and $\mathrm{HO}$ as common complications, with spasticity being the most frequent. Nearly half of the patients admitted to our center for rehabilitation had contractures at the time of admission, and nearly one-third had HO. This is alarming and reflects the lack of rehabilitation care during acute and subacute care after TBI. Thus, it is important to ensure early access to comprehensive rehabilitation in acute care facilities and to improve rehabilitation awareness among healthcare providers and other stakeholders involved in TBI care.

In this retrospective study, there were no associations with of age, gender, marital status, educational level, nature of occupation, etiology, or affected body side on functional outcomes. Age as a non-deciding factor was noted by Qannam et $\mathrm{al}^{6}$ and Gardner et al. ${ }^{29} \mathrm{On}$ the other hand, most studies have suggested that age is a determining factor for better motor and cognitive recovery ${ }^{22,30,31}$ and survival rates later in life. ${ }^{32-34}$ In one of the largest studies including 8719 patients investigating the association between age and functional outcome at 6 months, there was a strikingly linear relationship observed between age and outcome. ${ }^{35}$

The LOS has been analyzed in different perspectives. In one study, a reduced inpatient LOS did not adversely affect functional outcome one-year post brain injury; however, a multicenter study showed an evidence of significantly increasing daily cost of care with corresponding decreases in LOS. ${ }^{36,37}$ In our study, the initial GCS score in the ED and the LOS in the IPR facility were not associated with significant change in the FIM score at discharge. On the other hand, some studies have shown that the IPR LOS was associated with functional outcomes after TBI rehabilitation. ${ }^{22,26,38}$ Sandhaug et $\mathrm{a}^{25}$ reported that the predictors of the functional level at the time of discharge from rehabilitation were the GCS score at IPR admission and LOS in the rehabilitation unit. ${ }^{25} \mathrm{~A}$ review of the literature on TBI in older adults observed that shorter LOS and fewer hours of therapy per day in older people resulted in less functional ability both during and after IPR. ${ }^{29}$

In general, few Saudi studies have reported on LOS during acute care after TBI, but the time from injury to rehabilitation admission has been rarely reported. ${ }^{6}$ The average time from injury to IPR admission was 264 days in our study, which is similar to another recent report from Saudi Arabia by Qannam et al. ${ }^{6}$ It is interesting to observe that even though our average LOS was 11 days more as compared to this study, the FIM change was nearly similar. Additionally, our study included variables like comorbidities and complications post TBI. We analyzed different factors in relation to functional status, which have not been studied before in the region, and included employement status, educational level, occupation, and marital status. The LOS in acute care after TBI has been reported to be 50 and 94 days in local studies, but these reports do not mention if the patients underwent IPR after acute care. ${ }^{7,11}$ The duration from onset to admission to IPR is notably longer than that reported in studies from the United States and European countries. ${ }^{22,39-43}$ The apparent reason probably is the approach to trauma practice in Saudi Arabia. After major injuries associated with polytrauma, such as a head injury, the focus remains mainly on life-saving and limb-saving approaches in acute care. Patients might have prolonged intensive care and their activities might be confined to a bed on a surgical floor with limited access to comprehensive rehabilitation. Cognitive and behavioral aspects of the injury are often overlooked during this critical phase of recovery. Consequently, patients tend to develop complications, and their stay in acute care is prolonged. The need of continued care among dependent patients remains a considerable barrier for discharge, and the locations and resources for comprehensive rehabilitation are limited. There are few rehabilitation facilities offering comprehensive rehabilitation in the country, with a prolonged waiting time for admission and a limited number of beds for TBI. ${ }^{20}$ The mean LOS during rehabilitation was higher in our study ( 75 days) than in previous local studies (57 days and 64 days respectively). ${ }^{6,20}$ It is also higher than what is reported in studies from European countries, Australia, and USA. ${ }^{27,30,44-46}$ Presently, there is no general consensus on the optimal IPR LOS and the intensity of rehabilitation services for patients with TBI; however, there are guidelines, ${ }^{48-52}$ which vary from one health system to another.

Limitations. The present study had several limitations. First, this was a retrospective cohort study 
involving a single rehabilitation hospital, and thus, any generalization of the results to other facilities or countries should be made with caution. Secondly, there was limited diversity of outcome measures and insufficient information on the rehabilitation treatments received during acute care. Further studies involving more than one rehabilitation setups, with detailed documentation of the variety of rehabilitation services and evaluation based on multiple outcome measures would give a better picture of the effectiveness of rehabilitation procedures and protocols that may further lead to gradual improvement of these protocols.

Conclusion. For our cohort of TBI patients, the mean time from injury to IPR admission and the mean LOS in the IPR setup was longer than previous studies from Saudi Arabia. Reduction in disability at discharge was positively associated with the severity of disability at admission and negatively with the time duration from injury to IPR admission, indicating a need to reduce time before admittance to an IPR setup. The high incidence of MVA causing TBI in a young male population strongly points to a need for appropriate measures of prevention.

Acknowledgment. We would like to thank Enago, Crimson Interactive Inc. for English language editing.

\section{References}

1. Hyder AA, Wunderlich CA, Puvanachandra P, Gururaj G, Kobusingye OC. The impact of traumatic brain injuries: a global perspective. NeuroRehabilitation 2007; 22: 341-353.

2. James SL, Theadom A, Ellenbogen RG, Bannick MS, MontjoyVenning W, Lucchesi LR, et al. Global, regional, and national burden of traumatic brain injury and spinal cord injury, 1990-2016: a systematic analysis for the Global Burden of Disease Study 2016. Lancet Neurol 2019; 18: 56-87.

3. Roozenbeek B, Maas AI, Menon DK. Changing patterns in the epidemiology of traumatic brain injury. Nat Rev Neurol 2013; 9: 231-236.

4. Marehbian J, Muehlschlegel S, Edlow BL, Hinson HE, Hwang DY. Medical Management of the Severe Traumatic Brain Injury Patient. Neurocrit Care 2017; 27: 430-446.

5. Turner-Stokes L. Evidence for the effectiveness of multidisciplinary rehabilitation following acquired brain injury: a synthesis of two systematic approaches. J Rehabil Med 2008; 40: 691-701.

6. Qannam H, Mahmoud H, Mortenson WB. Traumatic brain injury rehabilitation in Riyadh, Saudi Arabia: Time to rehabilitation admission, length of stay and functional outcome. Brain Inj 2017; 31:702-708.

7. Arabi YM, Haddad S, Tamim HM, Al-Dawood A, Al-Qahtani S, Ferayan A, et al. Mortality reduction after implementing a clinical practice guidelines-based management protocol for severe traumatic brain injury. J Crit Care 2010; 25: 190-195.
8. World Health Organization. International statistical classification of diseases and related health problems, 10th revision. Fifth edition. WHO; CH (Geneva): 2016. from URL: https://apps.who.int/iris/handle/10665/246208

9. Granger CV, Hamilton BB, Zielezny M, Sherwin FS. Advances in functional assessment in medical rehabilitation. Top Geriatr Rehabil 1986; 1J: 59-74.

10. Al-Naami I, Al-Shehri S, Al-Ghamdi S, Ogran M, Qasem A, Medawi A, et al. Patterns, Types, and Outcomes of Head Injury in Aseer Region, Kingdom of Saudi Arabia. Neurosci J 2019; 2019.

11. Al-Habib A, A-Shail A, Alaqeel A, Zamakhshary M, Al-bedah K, AlQunai M, et al. Causes and patterns of adult traumatic head injuries in Saudi Arabia: implications for injury prevention. Ann Saudi Med 2013; 33: 351-355.

12. El-Siddig SM, Farahat HH, Mahmoud AA, Ajwah MAIM, Ajwah AM. Causes, patterns, and mortality of traumatic head injuries in a Tertiary Hospital in Tabuk, Saudi Arabia. Basic Res JMed Clin Sci 2017; 6: 93-98.

13. El-Menyar A, Consunji R, Al-Thani H, Mekkodathil A, Jabbour G, Alyafei KA. Pediatric Traumatic Brain Injury: a 5-year descriptive study from the National Trauma Center in Qatar. World J Emerg Surg 2017; 12: 48.

14. Taha MM, Barakat MI. Demographic Characteristics of Traumatic Brain Injury in Egypt: Hospital Based Study of 2124 Patients. J Spine Neurosurg 2016; 5: 6.

15. Al-Kuwaiti A, Hefny AF, Bellou A, Hani O, Abu-Zidan FM. Epidemiology of head injury in the United Arab Emirates. Ulus Travma Acil Cerrahi Derg 2012; 18: 213-218.

16. Adeloye A, al-Kuoka N, Ssembatya-Lule GC. Pattern of acute head injuries in Kuwait. East Afr Med J 1996; 73: 253-258.

17. Jamal A, Rahman MT, Al-Ahmadi HM, Mansoor U. The Dilemma of Road Safety in the Eastern Province of Saudi Arabia: Consequences and Prevention Strategies. Int J Environ Res Public Health 2019; 17: 1-23.

18. Mansuri FA, Al-Zalabani AH, Zalat MM, Qabshawi RI. Road safety and road traffic accidents in Saudi Arabia. A systematic review of existing evidence. Saudi Med J 2015; 36: 418-424.

19. Eilander HJ, Wijnen VJ, Scheirs JG, De Kort PL, Prevo AJ. Children and young adults in a prolonged unconscious state due to severe brain injury: outcome after an early intensive neurorehabilitation programme. Brain Inj 2005; 19: 425-436.

20. Al-Jadid MS, Robert AA. Length of stay of patients in different rehabilitation programs. A hospital experience in Saudi Arabia. Saudi Med J 2012; 33: 326-327.

21. DeNicola E, Aburizaize OS, Siddique A, Khwaja H, Carpenter DO. Road Traffic Injury as a Major Public Health Issue in the Kingdom of Saudi Arabia: A Review. Front Public Health 2016; 4: 215.

22. Demir Y, Köroğlu Ö, Tekin E, Kesikburun S, Güzelküçük $\ddot{U}$, Yilmaz B, et al. Factors affecting functional outcome in patients with traumatic brain injury sequelae: Our single-center experiences on brain injury rehabilitation. Turk J Phys Med Rehab 2019; 65: 67-73.

23. Andelic N, Bautz-Holter E, Ronning P, Olafsen K, Sigurdardottir $S$, Schanke AK, et al. Does an early onset and continuous chain of rehabilitation improve the long-term functional outcome of patients with severe traumatic brain injury? J Neurotrauma 2012; 29: 66-74.

24. Tepas JJ 3rd, Leaphart CL, Pieper P, Beaulieu CL, Spierre LR, Tuten JD, et al. The effect of delay in rehabilitation on outcome of severe traumatic brain injury. J Pediatr Surg 2009; 44: 273368-273372. 
25. Sandhaug M, Andelic N, Langhammer B, Mygland A. Functional level during the first 2 years after moderate and severe traumatic brain injury. Brain Inj 2015; 29: 1431-1438.

26. Cowen TD, Meythaler JM, DeVivo MJ, Ivie III CS, Lebow J, Novack TA. Influence of early variables in traumatic brain injury on functional independence measure scores and rehabilitation length of stay and charges. Arch Phys Med Rehabil 1995; 76: 797-803.

27. Tooth L, McKenna K, Strong J, Ottenbacher K, Connell J. Rehabilitation outcomes for brain injured patients in Australia: functional status, length of stay and discharge destination. Brain Inj 2001; 15: 613-631.

28. Ahmed S, Venigalla H, Mekala HM, Dar S, Hassan M, Ayub S. Traumatic Brain Injury and Neuropsychiatric Complications. Indian J Psychol Med 2017; 39: 114-121.

29. Gardner RC, Dams-O'Connor K, Morrissey MR, Manley GT. Geriatric Traumatic Brain Injury: Epidemiology, Outcomes, Knowledge Gaps, and Future Directions. J Neurotrauma 2018; 35: 889-906.

30. Frankel JE, Marwitz JH, Cifu DX, Kreutzer JS, Englander J, Rosenthal M. A follow-up study of older adults with traumatic brain injury: taking into account decreasing length of stay. Arch Phys Med Rehabil 2006; 87: 57-62.

31. Mosenthal AC, Livingston DH, Lavery RF, Knudson MM, Lee $S$, Morabito D, et al. The effect of age on functional outcome in mild traumatic brain injury: 6-month report of a prospective multicenter trial. J Trauma 2004; 56: 1042-1048.

32. Ramanathan DM, McWilliams N, Schatz P, Hillary FG. Epidemiological shifts in elderly traumatic brain injury: 18-year trends in Pennsylvania. J Neurotrauma 2012; 29: 1371-1378.

33. McIntyre A, Mehta S, Aubut J, Dijkers M, Teasell RW. Mortality among older adults after a traumatic brain injury: a meta-analysis. Brain Inj 2013; 27: 31-40.

34. Dams-O'Connor K, Gibbons LE, Bowen JD, McCurry SM, Larson EB, Crane PK. Risk for late-life re-injury, dementia and death among individuals with traumatic brain injury: a population-based study. J Neurol Neurosurg Psychiatry 2013; 84: 177-182.

35. Mushkudiani NA, Engel DC, Steyerberg EW, Butcher I, Lu J, Marmarou A, et al. Prognostic value of demographic characteristics in traumatic brain injury: results from the IMPACT study. J Neurotrauma 2007; 24: 259-269.

36. Hawkins ML, Lewis FD, Medeiros RS. Impact of length of stay on functional outcomes of TBI patients. The American surgeon 2005; 71: 920-929.

37. Kreutzer JS, Kolakowsky-Hayner SA, Ripley D, Cifu DX, Rosenthal M, Bushnik T, et al. Charges and lengths of stay for acute and inpatient rehabilitation treatment of traumatic brain injury 1990-1996. Brain injury 2001; 15: 763-774.

38. deGuise E, leBlanc J, Feyz M, Meyer K, Duplantie J, Thomas $\mathrm{H}$, et al. Long-term outcome after severe traumatic brain injury: the McGill interdisciplinary prospective study. J Head Trauma Rehabil 2008; 23: 294-303.
39. High WM Jr, Hall KM, Rosenthal M, Mann N, Zafonte R, Cifu D, et al. Factors Affecting Hospital Length of Stay and Charges Following Traumatic Brain Injury. J Head Trauma Rehabil 1996; 11: 85.

40. Cifu DX, Kreutzer JS, Marwitz JH, Rosenthal M, Englander J, High W. Functional outcomes of older adults with traumatic brain injury: a prospective, multicenter analysis. Arch Phys Med Rehabil 1996; 77: 883-888.

41. Eilander HJ, Wijnen VJ, Scheirs JG, De Kort PL, Prevo AJ. Children and young adults in a prolonged unconscious state due to severe brain injury: outcome after an early intensive neurorehabilitation programme. Brain Inj 2005; 19: 425-436.

42. Mazaux JM, De Sèze M, Joseph PA, Barat M. Early rehabilitation after severe brain injury: a French perspective. J Rehabil Med 2001; 33:99-109.

43. Corrigan JD, Cuthbert JP, Whiteneck GG, Dijkers MP, Coronado V, Heinemann AW, et al. Representativeness of the Traumatic Brain Injury Model Systems National Database. $J$ Head Trauma Rehabil 2012; 27: 391-403.

44. Avesani R, Carraro E, Armani G, Masiero S. Exploring variables associated with rehabilitation length of stay in brain injuries patients. Eur J Phys Rehabil Med 2012; 48: 433-441.

45. Zampolini M, Zaccaria B, Tolli V, Frustaci A, Franceschini M, GISCAR Group. Rehabilitation of traumatic brain injury in Italy: a multi-centred study. Brain Inj 2012; 26: 27-35.

46. Valk-Kleibeuker L, Heijenbrok-Kal MH, Ribbers GM. Mood after moderate and severe traumatic brain injury: a prospective cohort study. PLoS One 2014; 9: e87414.

47. Eastvold AD, Walker WC, Curtiss G, Schwab K, Vanderploeg RD. The differential contributions of posttraumatic amnesia duration and time since injury in prediction of functional outcomes following moderate-to-severe traumatic brain injury. J Head Trauma Rehabil 2013; 28: 48-58.

48. Dash HH, Chavali S. Management of traumatic brain injury patients. Korean J Anesthesiol 2018; 71: 12-21.

49. Lee SY, Amatya B, Judson R, Truesdale M, Reinhardt JD, Uddin T, et al. Clinical practice guidelines for rehabilitation in traumatic brain injury: a critical appraisal. Brain Inj 2019; 33: 1263-1271.

50. Downing M, Bragge P, Ponsford J. Cognitive Rehabilitation Following Traumatic Brain Injury: A Survey of Current Practice in Australia. Brain Impairment 2019; 20: 24-36

51. Chowdhury T, Kowalski S, Arabi Y, Dash HH. Pre-hospital and initial management of head injury patients: An update. Saudi J Anaesth 2014; 8: 114-120.

52. Bragge P, Pattuwage L, Marshall S, Pitt V, Piccenna L, StergiouKita M, et al. Quality of guidelines for cognitive rehabilitation following traumatic brain injury. J Head Trauma Rehabil 2014; 29: 277-289.9-437. 